\title{
Planejamento Cooperativo e Tecnologias Digitais na Formação de Professores de Matemática
}

\author{
Marcus Vinicius de Azevedo Basso \\ Universidade Federal do Rio Grande do Sul - Instituto de Matemática \\ mbasso@ufrgs.br
}

\begin{abstract}
Resumo
A utilização de recursos tecnológicos na formação inicial de professores de Matemática têm sido um dos pontos centrais do Curso de Licenciatura em Matemática de Universidade Federal do Rio Grande do Sul. Nesse artigo abordamos o papel do planejamento cooperativo e a utilização das tecnologias de comunicação na formação de licenciandos em Matemática.
\end{abstract}

Palavras-chave: cooperação, formação de professores, matemática

\section{Cooperative planning and Digital Technologies in Training Teachers of Mathematics}

Abstract

The use of technological resources in mathematics teacher's preparation undergraduate course has been one of the points central offices of the Teacher Preparation Undergraduate Course in Mathematics of the Federal University of the Rio Grande do Sul. In this article we approach the paper of the cooperative planning and the use of the technologies of communication in the training of future teachers of Mathematics.

Keywords: cooperation, training teachers, mathematics

1. Introdução

O mito da Torre de Babel tem inspirado pintores, escritores, cientistas ao longo dos séculos. Brüegel se insere neste círculo de artistas com "A Torre de Babel" de 1563, quadro que faz parte do acervo do Kunsthistorisches Museum, Viena (figura 1)

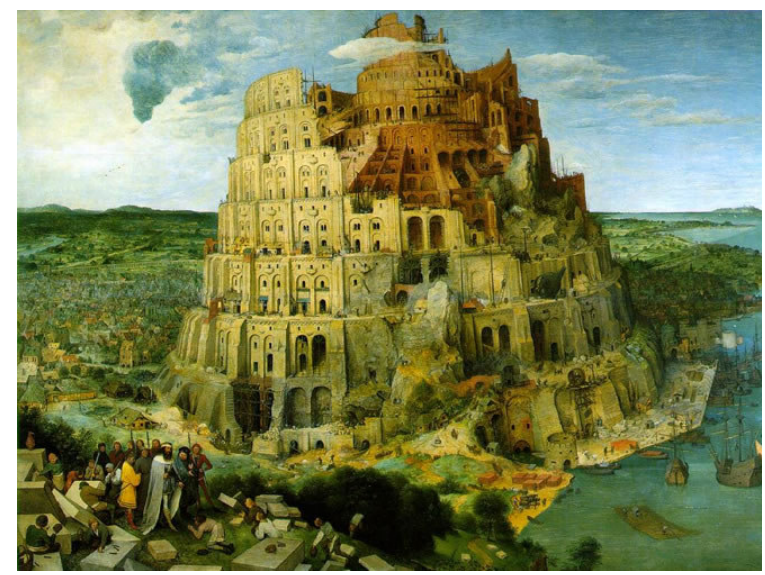

Figura 1: A Torre de Babel

A "Torre de Babel" por vezes é utilizada como metáfora para caracterizar alguns aspectos da Política, da Economia, das Comunicações e, como caso particular dessa última, a internet. No caso da Internet, caracterizar e discutir a respeito das dificuldades para encontrar informações sobre algum assunto pesquisado; veracidade/falsidade das informações disponíveis; encontro e confronto de múltiplas idéias; múltiplas línguas; uma "Babel". No caso do presente artigo, 
dando continuidade a estudo iniciado e defendido na tese "Espaços de aprendizagem em rede: novas orientações na formação de professores de Matemática" (Basso, 2003), utilizo a metáfora da Torre de Babel para caracterizar o contexto dos encontros e desencontros que ocorrem quando estudantes do ensino superior trabalham e discutem a respeito de noções e conceitos em Matemática com o objetivo de planejar e implementar propostas de ensinoaprendizagem destinadas para alunos do ensino básico. Tal contexto é construído a partir do trabalho que estudantes do Curso de Licenciatura desenvolvem nas chamadas disciplinas Laboratório de Prática de Ensino-aprendizagem em Matemática que, por sua vez, fazem parte do currículo do Curso de Licenciatura em Matemática da UFRGS. A modalidade do trabalho executado nessas disciplinas não é única e nesse trabalho apresentaremos uma dessas formas, a qual está fortemente baseada na utilização de recursos tecnológicos na formação inicial de professores de Matemática, um dos pontos centrais do Curso de Licenciatura em Matemática da Universidade Federal do Rio Grande do Sul, e na criação de grupos de trabalho para planejar e implementar tal planejamento junto a estudantes do ensino básico.

Tal estudo reveste-se de importância na medida em que as escolas das redes privada e pública, a cada dia, estão instalando ambientes informatizados e os futuros professores necessitarão lidar com essa realidade tão logo concluam seus estudos universitários.

Além disso, o ambiente escolar é notadamente um ambiente no qual há a necessidade dos profissionais em educação trabalharem em equipes. Assim, procuramos analisar possíveis contribuições dos recursos oferecidos pelas tecnologias da informação e comunicação na formação de licenciandos em Matemática, principalmente do ponto de vista do desenvolvimento de trabalhos cooperativos.

\section{Transformações na cultura e a cultura das escolas}

Em 1948, a pedido da Comissão Internacional para o Desenvolvimento da Educação da UNESCO, Piaget escreveu um artigo cujo título é a primeira frase do artigo 26 da Declaração Universal dos Direitos do Homem, votada pelas Nações Unidas no mesmo ano e que diz: "Toda pessoa tem direito à educação." No artigo, Piaget ressalta que a preocupação da Comissão foi a de colocar em evidência as obrigações da sociedade para com o indivíduo a ser educado e também, igualmente importante, enfatizar a "indispensável solidariedade que associa o desenvolvimento pessoal ao respeito pelo outro" (Piaget, 1971, p. 28). Argumentando segundo sua perspectiva epistemológica, Piaget ressalta que:

"As principais condições sociais do homem, ou seja, os meios técnicos de produção, a linguagem com o conjunto das noções por ela possibilitados, as regras e os costumes, não são pré-determinadas por mecanismos hereditários prontos a serem ativados ao contato com as coisas e com aqueles que estão perto" (Piaget, 1971, p. 30).

Ao contrário, diz ele, "tais comportamentos são adquiridos por transmissão exterior, de geração em geração", isto é, via educação. Ou seja, as múltiplas e diferenciadas interações sociais é que possibilitarão tal desenvolvimento. É evidente a importância que Piaget atribuiu à Educação na formação intelectual e moral do homem. No entanto, o fracionamento e pulverização das matérias que compõem os currículos escolares dos sistemas de ensino de todos os níveis (p. 13) representavam - à época do texto de Piaget - um entrave para a concretização da proposição do artigo 26 da Declaração Universal dos Direitos do Homem. Uma das ações a serem implementadas para remover este obstáculo seria a de criar condições para o desenvolvimento de propostas com caráter interdisciplinar na iniciação científica em todos os níveis, acompanhado pela valorização do papel dos professores e, concomitantemente, melhorar a formação dos mesmos. Tal formação deveria contemplar, mais do que os conhecimentos de uma didática especializada, a compreensão da necessidade de ser enfatizada a "pesquisa espontânea, quer seja por uma criança ou um adolescente e que toda a verdade a ser adquirida seja reinventada pelo aluno, ou pelo menos reconstruída e não simplesmente transmitida". (Piaget, 1971, p. 15)

Tão atual e muito similar quanto às idéias expressas no artigo 26 e nas proposições de Piaget, Comenius, no clássico Didactica Magna escrito no Século XV, preconizava:

"É necessário que toda a juventude receba uma formação conjunta, nas escolas." 
"A educação nas escolas deve ser universal."

"As escolas podem ser reformadas e melhoradas." (Comenius, 1997, p. VI)

Passados três séculos entre os registros de Comenius e os da ONU, a situação parece inalterada. Isto não significa que esforços para melhorar tanto a formação dos professores quanto a compreensão do papel que a Educação pode e deve desempenhar na educação intelectual e moral ou, dito de outra forma, formação integral de crianças e adolescentes, não tenham sido tentados. Os esforços neste sentido continuam sendo feitos e aponto o paralelo entre o que defendia Piaget - e antes dele Comenius - com o documento organizado por Jacques Delors, presidente da Comissão Internacional sobre a Educação para o Século XXI - UNESCO.

Nesse documento, "La Educación Encierra Un Tesoro" (Delors, 1993), Educação aqui compreendida como sendo a que se realiza ao longo da vida, se destaca o que a Comissão intitulou de "Os Quatro Pilares da Educação" (Delors, 1993, p 36):

- Aprender a aprender.

- Aprender a fazer.

- Aprender a conviver.

- Aprender a ser.

Aprender a aprender, combinando uma cultura geral suficientemente ampla com a possibilidade de aprofundar os conhecimentos em um reduzido número de matérias. Além disso, aprender a aprender para poder aproveitar as possibilidades que a Educação oferece ao longo da vida.

Aprender a fazer a fim de adquirir não apenas uma qualificação profissional, mas também, de maneira mais geral, uma competência que capacite o indivíduo para fazer frente à diferentes situações e a trabalhar em equipe.

Aprender a conviver desenvolvendo a compreensão do outro e a percepção das diversas formas de interdependência, isto é, realizar projetos comuns, preparar-se para lidar com conflitos, respeitando os valores do pluralismo, da compreensão mútua e da paz.

Aprender a ser para que se desenvolva melhor a própria personalidade criando condições para trabalhar com autonomia, juízo e responsabilidade. Para atingir tal objetivo, a Educação deve valorizar, para cada indivíduo, sua memória, raciocínio, senso estético, capacidades físicas e atitudes para comunicar.

Ressalta ainda o documento que, pelo fato dos sistemas formais de educação favorecerem prioritariamente a aquisição de conhecimentos, em detrimentos de outras formas de aprendizagem, é importante conceber a Educação como um todo.

Concebendo a Educação desta forma, há necessidade de estabelecer novas orientações para realizar reformas educativas, tanto na elaboração de novos currículos quanto na definição de novas políticas pedagógicas. Comenius, por volta de 1650, Piaget em 1948, Delors e a Comissão da UNESCO em 1993: os três apontam a necessidade de existirem reformas profundas na Educação. Reformas que não excluem a importância dos conhecimentos acumulados pela humanidade serem apreendidos por crianças e adolescentes. No entanto, nos três podemos identificar que não é o acúmulo de conhecimentos o que importa. Importa sim priorizar a compreensão dos mesmos, priorizar a possibilidade de criar, de reinventar. Para Piaget, este compreender significa inventar ou reconstruir através da invenção e, somente assim, será possível estabelecer as condições para o desenvolvimento de indivíduos capazes de produzir ou de criar e não apenas de repetir. (Piaget, 1948, p. 17) Mas, apesar da validade das propostas apresentadas, a Escola continua resistente a mudanças. Que razões poderiam ser apontadas para isto?

Vejamos um exemplo da contradição que vive a Escola.

"A escola tradicional oferece ao aluno uma quantidade considerável de conhecimentos e lhe proporciona a ocasião de aplicá-los em problemas e exercícios variados: ela enriquece" assim o pensamento e o submete, como se costuma dizer, a uma "ginástica intelectual", à qual caberia consolidá-lo e desenvolvê-lo. No caso do esquecimento (e todos sabemos o pouco que resta dos conhecimentos adquiridos na Escola, cinco, dez ou vinte anos após o término dos estudos secundários), tem ela ao menos a satisfação 
de haver exercitado a inteligência; pouco importa que se haja esquecido por completo a definição do co-seno, as regras da quarta conjugação latina ou as datas da história militar: o essencial é tê-las conhecido. (...) se subsiste tão pouca coisa dos conhecimentos registrados por encomenda, a extensão do programa importa menos que a qualidade do trabalho. Conquistar por si mesmo um certo saber, com a realização de pesquisas livres, e por meio de um esforço espontâneo, levará a retê-lo muito mais; isso possibilitará sobretudo ao aluno a aquisição de um método que lhe será útil por toda a vida e aumentará permanentemente a sua curiosidade, sem o risco de estancá-Ia; quando mais não seja, ao invés de deixar que a memória prevaleça sobre o raciocínio, ou submeter a inteligência a exercícios impostos de fora, aprenderá ele a fazer por si mesmo funcionar a sua razão e construirá livremente suas próprias noções. (p. 53-54)

A implementação de uma proposta assim, choca-se com a falsa questão: $O$ papel do professor será anulado? A questão é falsa porque o que se coloca é a mudança do papel do professor. Espera-se que ele crie as situações e dispositivos capazes de suscitar problemas úteis às crianças e adolescentes. Espera-se também que ele seja capaz de organizar contra-exemplos que levem à reflexão. Ou seja, deixar de ser um conferencista e que estimule a pesquisa e o esforço, ao invés de contentar-se com a transmissão de soluções já prontas. (p. 15) Se superado este primeiro temor da Escola e, em particular dos professores, qual seja, que seu papel é extremamente importante mas precisa ser modificado profundamente, temos atualmente um outro problema a enfrentar. Aos professores se pede que, além de tentar acompanhar o crescimento e as reestruturações nos conteúdos de sua área de especialização, que eles aprendam como o ser humano pensa e como ele aprende e eles venham a se apoderar das novas tecnologias. A aprendizagem do uso dessas tecnologias, em alguns casos, têm repetido os procedimentos que ocorriam na escola sem ela e, neste caso, muito provavelmente o estado atual da educação será mantido. Fundamental é descobrir como usá-la para alcançar resultados que aproveitem o máximo de rendimento de suas características específicas e inusuais. (Fagundes, 1988, p. 5). Que preparação estes professores poderiam ter de maneira que suas desconfianças sejam minimizadas em relação ao uso das novas tecnologias e se sintam mais seguros para promover as mudanças esperadas?

Valem aqui os mesmos princípios do documento da UNESCO. A preparação dos professores deveria contemplar o uso das tecnologias digitais desde os primeiros momentos de sua formação inicial, enfatizando as habilidades para aprender a aprender, aprender a pensar, aprender a fazer e aprender a conviver. Ou seja, a preparação contemplaria os mesmos princípios que são esperados para ocorrerem no espaço de trabalho das crianças e adolescentes que este futuro professor encontrará. Este futuro professor também deveria ter a liberdade para desenvolver e colocar em prática os seus projetos, suas pesquisas, testar as suas hipóteses e refletir a partir de suas experiências.

Tais experiências, por sua vez, podem ser orientadas por professores que promovam ações voltadas para o exercício dos princípios citados. Neste caso, as atividades deveriam enfatizar possibilidades dos futuros professores:

A. criarem e exercitarem novas práticas em Escolas;

B. trabalharem em equipe no planejamento de atividades a serem desenvolvidas com crianças e adolescentes;

C. trabalharem em equipe com seus próprios alunos na Escola;

D. utilizarem os recursos digitais oferecidos pelas novas tecnologias tanto no planejamento com seus colegas quanto no trabalho com alunos em Escolas

A implementação de uma proposta construída nestas bases poderia provocar um duplo movimento, representado pelo diagrama a seguir? 


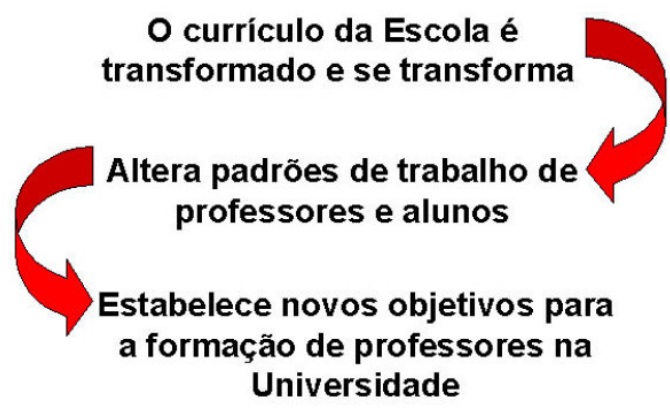

Figura 2: duplo movimento de formação/transformação

Por outro lado, embora estes sejam princípios gerais e, portanto, aplicáveis a futuros professores de quaisquer áreas, no presente estudo, o trabalho foi desenvolvido com estudantes de uma licenciatura específica: Matemática. Alguma coisa se modifica neste caso? A diferença reside na particularidade do conhecimento da área deste futuro professor. Ou seja, valem os princípios enunciados agregados aos conhecimentos da área. A apropriação da tecnologia não seria um fim em si. Ela estaria à disposição desse estudante de licenciatura para que dela fizesse uso:

- na aprendizagem e pesquisa de conceitos em matemática

- no estabelecimento de relações com outras áreas do conhecimento

- no planejamento e desenvolvimento de propostas compartilhadas com seus colegas e com seus alunos

- na redefinição de fins, objetivos e metas

- na reestruturação de tempos e espaços

- na avaliação de processos quantitativos e qualitativos

- na produção e autoria

Assim como a metáfora da Torre de Babel é utilizada em várias áreas, o mesmo se pode dizer em relação ao tema cooperação. As atividades de pesquisa e ensino, desenvolvidas nos níveis de ensino fundamental, médio e superior nos últimos anos, têm me suscitado algumas dúvidas.

1. Que reflexos o uso dessa rede de comunicações pode para a formação do futuro professor de Matemática?

2. A implementação de uma proposta construída segundo as bases explicitadas nos itens A, B, C e $\mathrm{D}$ poderia provocar um duplo movimento, representado pelo diagrama apresentando na figura $2 ?$

\section{Materiais e Técnicas}

Segundo Damásio (Damásio, 2000, p. 112), "Embora em certa medida estejamos condenados a estudar a consciência por vias indiretas, essa limitação não se restringe à consciência. Aplicase a todos os demais fenômenos cognitivos". Em particular, a afirmação de Damásio aplica-se aos fenômenos que pretendemos investigar e "goste-se ou não, todos os conteúdos de nossa mente são subjetivos e o poder da ciência provém de sua capacidade para comprovar ou refutar objetivamente a consistência de muitas subjetividades individuais." (Damásio, 2000). Concordando com Damásio, é possível tratar cientificamente os fenômenos subjetivos ainda que tenhamos acesso a elas somente pela via indireta. Para isso devemos nos acercar de um consistente conjunto de dados tendo claro que "A consciência ocorre no interior de um organismo e não em público, mas se associa a várias manifestações públicas. Essas manifestações não descrevem o processo interno de todo tão direto quanto uma sentença falada traduz um pensamento, e no entanto, quando disponíveis para observação, elas são como correlatos e sinais reveladores da presença da consciência."

Especificamente, lidaremos com "as manifestações internas correspondentes do ser humano que as está apresentando, conforme elas são relatadas por esse ser humano", acrescidas das manifestações gráficas representadas pelos sujeitos nessa pesquisa. 
Para isso, designaremos como experiência, o contexto no qual as atividades a serem desenvolvidas pelos sujeitos envolvidos neste estudo ocorrerão. Estando de acordo com a metodologia de investigação proposta por Jean Piaget, é importante caracterizar dois tipos de experiências que serão investigadas:

- Experiência física: que consiste em agir sobre os objetos para descobrir as propriedades deles;

- Experiência lógico-matemática: que consiste também em agir sobre os objetos. Mas, a abstração das informações são obtidas das ações que resultam em modificações quando exercidas sobre os objetos. (Grize, 1981).

A obtenção dos dados relativos a processos de cooperação, nesta proposta de investigação, fez uso de ambientes digitais de aprendizagem (ADAs) conectados via Web como condição necessária. Nos dois ambientes utilizados (Mathematikos e Mathema) estavam disponíveis recursos de comunicação (chat e fórum) e de publicação de páginas. Além desses recursos, foram utilizadas listas de correio eletrônico para os envolvidos no trabalho e outros softwares (Cabri-Géomètre, Home- Design 3D, CMap, editores de textos, editores de imagens e navegadores para Internet).

\section{Sujeitos}

No presente trabalho destacamos como grupo de sujeitos que foram investigados, o grupo de alunos matriculados regularmente nas disciplinas de Laboratório de Ensinoaprendizagem de Matemática Elementar I e II do Curso de Licenciatura em Matemática - Instituto de Matemática - UFRGS.

\section{Trabalho experimental, dados e análise}

Para a análise dos dados obtidos a partir da produção do grupo investigado, examinamos o levantamento das produções de 13 alunos da Licenciatura em Matemática durante a situação de planejamento e prática das atividades a serem executadas com os alunos do Ensino Fundamental. As súmulas das disciplinas de Laboratório de Prática de Ensino de Matemática I e II do Curso de Licenciatura em Matemática - Instituto de Matemática - UFRGS comportam o desenvolvimento de atividades relacionadas com a seleção, preparação, montagem, execução e avaliação de experiências de prática de ensino de tópicos de aritmética, contagem e Geometria para alunos dos ensinos Fundamental e Médio. Nesta fase os estudantes de Matemática participaram, como professores, das Assessorias de Matemática e de Interação Virtual em duas Escolas de Ensino Fundamental - Colégio de Aplicação - Projeto Amora e Escola Municipal Vila Monte Cristo, ambas em Porto Alegre -, sendo orientados a planejar e executar atividades envolvendo basicamente conhecimentos de aritmética e geometria elementares.

Constituem dados desse grupo:

- diários de bordo

- relatórios para a disciplina

- interações via correio eletrônico

- trabalhos de conclusão da disciplina

- registros de planejamentos feitos em formulários

- páginas construídas pelos estudantes para o ambiente Mathema

Em termos de sistemática de trabalho e pesquisa, realizávamos uma reunião semanal de planejamento e mantínhamos uma lista de correio eletrônico que servisse de suporte para possíveis, se necessárias, complementações. Além desse recurso, dois espaços foram criados no ambiente Mathematikos: um foi destinado exclusivamente para os estudantes de Matemática e outro para os alunos do CAp-Amora. No primeiro destes espaços, os alunos tinham acesso à ferramentas para publicação de seus diários, agenda, fórum, formulários para envio dos pareceres trimestrais dos estudantes do CAp-Amora, um repositório dos trabalhos produzidos pelos por seus alunos - incluindo imagens fotográficas e uma pequena biblioteca com textos relacionados com o próprio trabalho.

Os registros diários dos estudantes de Matemática serviriam para que eles pudessem acompanhar o desenvolvimento e aprendizagens de seus alunos e também como um importante 
suporte para a elaboração de um trabalho de conclusão. A necessidade de desenvolver tal trabalho de conclusão foi justificada com base no pressuposto que o caráter prático do trabalho que eles estavam realizando forneceria dados experimentais que mereceriam uma reflexão mais sistematizada.

$\mathrm{Na}$ mensagem a seguir, temos uma das primeiras manifestações com relação ao exercício de planejamento do grupo.

\section{De: $C S A$}

Assunto: Idéias...

Oi, gente!

Estou desde quinta-feira pensando em alguma atividade para ser posta em prática na sala de aula, mas até agora não consegui imaginar nada muito aproveitável (na minha opinião). Cheguei a pensar em algo ligado a preços de alguns produtos, como por exemplo em uma feira onde temos preços usando números com vírgula relacionados com o peso do produto. Mas não sei se essa atividade já foi realizada...

Poderíamos também aproveitar algum dos trabalhos que fizemos em Ensino I. Ou ainda, fazer uma espécie de pesquisa com os alunos perguntando onde eles já viram números decimais. Assim, poderemos selecionar um assunto de interesse deles e desenvolver uma atividade mais direcionada.

E então o que acham? Espero respostas e opiniões.

OBS.: Prof. Marcus, qual é o endereço do site citado na quinta-feira onde poderíamos ver exemplos de atividades desenvolvidas anteriormente? Por favor, precisamos de uma "luz".

\section{Mensagem 7: lista LabMatPesq}

O menos importante na presente situação é se o professor da disciplina deu alguma "luz", mas sim que um dos colegas da turma anterior imediatamente veio em auxílio da nova parceira de trabalho.

\section{De: $M S C$}

Assunto: Voltando à ativa

bem... (...)

MAM, já enviei minha opinião pra lista toda, aquele mail q tu leu acabou indo pra todo mundo pq enviei praquele endereço citado (labmatpesq@yahoogroups.com)...

CSA, já tinha enviado antes os endereços dos sites, mas não custa repetir:

2001 - http://mathema.psico.ufrgs.br/laboramat 2001

2000 - http://assessoriamat.cjb.net/

quanto ao q tu tava falando a respeito de pensar, pensar, e não surgir nenhuma ideía, não te assusta: é normal acontecer isso...

sobre a atividade da feira, vou (foi) realizado algo parecido, mas o grupo de quinta não chegou a trabalhar com ela... podemos discutir mais sobre ela...

\section{Mensagem 8: lista LabMatPesq}

E, se a questão envolve ter idéias, a Internet também pode auxiliar, como nas sugestões enviadas por RUR, outra estudante do grupo.

\section{De: $R U R$}

Assunto: Endereços_de_Matemática

Oi Pessoal! Recebi de uma amiga estes endereços de sites de matemática, ainda não olhei todos, mas podem ser interessantes. Dêem uma olhadinha! (...)

ser interessantes. Dêem uma olhadinha! (...)

\section{Mensagem 19: lista LabMatPesq}

Alguns poucos dias foram suficientes para que uma nova proposta, já bastantes organizada e viável, surgisse como resultado das discussões do grupo:

\section{De: $C S A$}

Assunto: Proposta de trabalho

(...) estou escrevendo sobre a idéia de trabalho dada numa das nossas reuniões da semana 
passada; principalmente porque agora já vimos um pouco do home design.

Uma coisa que eu notei é que vai ser difícil manter a atenção das crianças no objetivo do trabalho. Tinha pensado inicialmente em cada grupo fazendo um bairro que no final poderiam ser agrupados formando uma cidade. Outra coisa que me ocorreu, é que outra disciplina abordasse o que uma cidade necessita ter para atender a todas as necessidades dos seus habitantes (como por exemplo: hospital, escola, praça...). Notei no dia da gravação que nesse trabalho também poderemos abordar a proporcionalidade e a viabilidade das construções deles. $O$ aluno que apresentou a casa na gravação fez uma casa de 3 quartos de $2 m \times 2 m$, um banheiro de $2 m \times 2,5 m$;

coisas praticamente inviáveis; até porque a casa de trinta metros quadrados era para 5 pessoas. Já tentaram imaginar isso?

Com esse trabalho poderíamos abordar vários assuntos: proporcionalidade, escala, conversão de medidas (que seria uma continuação do trabalho com o multibase), formas geométricas, área, perímetro, visualização em $3 d$ e talvez outros que eu ainda não percebi.

Pensando melhor sobre a ordem (computador ou maquete primeiro) cheguei à conclusão de que realmente será mais proveitoso e atrativo fazer os projetos no computador. A maquete poderia ser realizada junto com as atividades de Educação

Artística (se é que essa matéria ainda existe) ou em uma oficina especial.

Bom, essa é mais ou menos a minha idéia. Qualquer pergunta ou sugestão me mandem um email. Toda ajuda é bem-vinda. Estou pensando em mais coisas que podem ser abordadas nesse trabalho.

\section{Mensagem 22: lista LabMatPesq}

Observa-se ainda, que muitas outras possibilidades que conceitos surgem a partir dessa primeira proposta apresentada pelo grupo. O universo de noções e conceitos amplia-se e, como a própria mensagem comprova, "mais coisas podem ser abordadas" além das já explicitadas. Além desse aspecto relevante, qual seja, o da abertura de possibilidades inicialmente não imaginadas, a proposta apresentada é a síntese do trabalho que um grupo. CSA, neste momento, é uma das parceiras de um trabalho que está sendo realizado por uma equipe que tinha, naquele instante, objetivos comuns. Mas, como toda e qualquer proposta, esta também estava sujeita às sugestões e compartilhamentos de opiniões que, neste caso, partiram de um dos integrantes do grupo.

\section{De: $M S C$}

Assunto: Re: Proposta de trabalho

CSA escreveu: (...) notei que o pessoal se distraía muito com detalhes da casa, como os móveis, cor, etc. (...) teremos que pensar numa forma de resolver esse problema.

MSC escreveu: realmente, CSC, quando trabalhamos com o home design, no segundo semestre do ano 2000, a atividade praticamente inexistiu depois q descobriram a possibilidade de uso dos móveis.... foi consenso entre nós q, para futuras utilizações do

programa, é fundamental q se delete os arquivos dos movéis, cortando o mal pela raiz...

o q ves acham?

CSA escreveu: (...) Tinha pensado inicialmente em cada grupo fazendo um bairro que no final poderiam ser agrupados formando uma cidade. Outra coisa que me ocorreu, é que outra disciplina abordasse o que uma cidade necessita ter para atender a todas as necessidades dos seus habitantes (como por exemplo: hospital, escola, praça...).

MSC escreveu: a idéia de integração com outras disciplinas é muito boa, e deve ser tentado isso sempre, mesmo q muitas vezes não consigamos... toda quinta-feira, no período de aulas, ocorre uma reunião entre os professores e assessores do amora, e podemos aproveitar pra discutir a viabilidade de tal integração...

CSC escreveu: (...) também poderemos abordar a proporcionalidade e a viabilidade das construções deles. O aluno (...) fez uma casa de 3 quartos de $2 m \times 2 m$, um banheiro de $2 m x 2,5 m$; coisas praticamente inviáveis (...)

MSC escreveu: essa também foi uma falha q apareceu quando trabalhamos com eles apareceram, por exemplo, portas de $30 \mathrm{~cm}$... é importante ressaltar para os alunos se preocuparem com as medidas, pq o programa não deixa claro, à primeira vista, a importância 
delas....

Mensagem 23: lista LabMatPesq

Em seguida à mensagem 23, MLS, uma colega do grupo pondera na mensagem 24 sobre outros aspectos relacionados com o uso que as crianças fazem dos objetos que são colocados virtualmente nos projetos das casas, contrapondo-se à argumentação de MSC.

Este, por sua vez (mensagem 25), concordará parcialmente com MLS apontando um novo problema.

De: $M L S$

Assunto: trabalho com os alunos

(...) Li as observações do MSC a respeito das crianças usarem ou não móveis no planejamento das casas. Entendo que isso distrai consideravelmente a atenção dos alunos mas por outro lado os ajuda a dar a noção de proporcionalidade que faltou no trabalho citado por ele. Usando móveis eles vão saber dimensionar bem as peças da casa. Mas acho que este não é o objetivo principal do tabalho. Concordam?

Depois da casa feita no computador, sugiro que os aluno construiam a maquete e então passem para o trabalho do cálculo de áreas, orçamentos com pesquisa de preços etc...Acho que junto as sugestões da CSC em relação a construção de bairros e do MSC com a pesquisa das necessidades de uma cidade teremos trabalho para mais de um semestre.

\section{Mensagem 24: lista LabMatPesq}

\section{De: $M S C$}

Assunto: Re: trabalho com os alunos

realmente, os móveis poderiam ajudar as crianças a se darem conta de q precisam lidar com as medidas, se não fosse por um detalhe: o tamanho dos móveis pode ser ajustado, possibilitando sofás de $10 \mathrm{~cm}$, por exemplo....

\section{Mensagem 25: lista LabMatPesq}

Paralelamente às discussões sobre o Home Design, o grupo começa a discutir o uso do software Cabri-Gèométre. Nas mensagens de MAM e CSC (mensagens 39 e 41) há evidências que a proposta do grupo já contempla, de forma consciente, aspectos relacionados com a aprendizagem dos alunos.

\section{De: $M A M$}

Assunto: Cabri

(...) Acho que a atividade estava se tornando proveitosa, pois eles já estavam entendendo a utilização do Cabri, então sugiro para que a atividade continue segunda que vem e que no final seja feita a apresentação de cada dupla, revelando o que aprenderam e as dificuldades encontradas.

\section{Mensagem 39: lista LabMatPesq}

\section{De: $C S C$}

Assunto: Re: Cabri

MAM, concordo contigo. Achei que o trabalho com o cabri evoluiu muito apesar de que eles continuam encontrando problemas para relacionar o programa e a geometria. Por exemplo: na dupla que eu estava trabalhando eles não tinham idéia de como fazer uma reta tangente à uma circunferência; achavam que era só fazer uma reta, fazer uma circunferência e grudar as duas coisas ou sobrepô-las. Também acho que seria interessante eles apresentarem os trabalhos $e$ as dificuldades. Isso seria bom para eles

(que poderiam, com a nossa ajuda e com a ajuda dos colegas resolver os problemas) e para nós (que saberíamos como e o que melhorar no nosso "auxilio"). Vale a pena conversar isso com o Marcus. Até a próxima segunda-feira.

11

Obs.: Acho que, até agora, essa última segunda-feira foi a mais proveitosa para nós.

Acredito que a maioria gostou desse trabalho e viu resultados dele (ou pelo menos uma 
perspectiva de resultado).

\section{Mensagem 41: lista LabMatPesq}

O que era para ser apenas uma síntese das discussões (mensagem 45) gerou novas trocas de argumentos, agora com relação à apropriação de conceitos em Geometria e o uso, de uma determinada maneira, do software Cabri-Gèométre. Tal discussão envolveu vários estudantes, com idas e vindas nas argumentações e contra-argumentações, produção de exemplos e contraexemplos e a permanente disposição para o entender o ponto de vista do outro. (mensagens 46, 47 e 48$)$

De: $M S C$

Assunto: Re: Relato do encontro (08/10)

Renata escreveu: Comentou-se que o software poderia tornar o trabalho com Geometria bem mais interessante e que para se trabalhar com o mesmo é indispensável um conhecimento, mesmo que mínimo, em Geometria e seus conceitos.

MSC respondeu: na hora da reunião não me manifestei, mas discordo desse ponto de vista, na parte sobre ser indispensável ter conhecimentos de geometria... na oficina q trabalhei junto com o becker no aplicação, com os alunos do amora, nenhum tinha conhecimento teórico de geometria, apenas alguns conceitos empíricos... acho q um ponto forte do cabri é fazer com $q$ os conceitos geométricos se tornem necessários para a construção de projetos, sendo assim viável uma aprendizagem simultânea à construção, e não alguns postulados e teoremas soltos no quadro-negro... o q vcs acham?

\section{Mensagem 46: lista LabMatPesq}

\section{De: $C S C$}

Assunto: Re: Relato do encontro (08/10)

Bom, MSC, eu concordo e discordo de ti...acho que algumas noções teóricas são necessárias, nada muito sofisticado, sem teoremas e postulados.

Apenas o básico. Porém, outros conceitos mais abstratos, aqueles que não conseguimos visualizar tão facilmente, recebem uma ajuda importantíssima do Cabri. (...) Talvez tanto a tua opinião quanto a dita na reunião estejam certas cada uma de acordo com a forma de trabalho e desenvoltura de cada turma frente ao computador e ao próprio programa. A minha opinião final é o seguinte: as duas situações estão certas dependendo da forma de aplicação do trabalho e da turma. Concorda? Cada turma se adapta a uma forma de trabalhar, cabe a nós e aos próprios alunos descobrir qual vai dar o melhor resultado.

\section{Mensagem 47: lista LabMatPesq}

De: $M S C$

Assunto: Re: Relato do encontro (08/10)

CSC escreveu: Bom, MSC, eu concordo e discordo de ti...acho que algumas noções teóricas são necessárias, nada muito sofisticado, sem teoremas e postulados.

MSC escreveu: quais noções tu acha importante?

hummm... sinceramente, agora não me lembro de nenhum q não tenha utilidade em projetos.. até mesmo a inversão, a meu ver a transformação mais complexa (e mais legal), pode ser usada para uns desenhos muito legais.. de novo, vou te pedir exemplos, talvez tu esteja enxergando algo q eu não tenha me dado conta....não só cada turma, mas o cabri também é bastante flexível... tu pode fazer coisas tri avançadas ou dar uma aula super tradicional....

\section{Mensagem 48: lista LabMatPesq}

O exercício da autonomia, uma característica importante na formação do futuro professor, também está presente nas ações do grupo. Uma das primeiras manifestações da construção da autonomia do grupo está expressa na mensagem 58. Nesta situação, não é a presença do professor que determina o compromisso a ser assumido. Ou seja, o compromisso se estabelece por um acordo interno ao grupo, um acordo entre iguais e sem coação.

De: CSC 
Assunto: Reunião de segunda-feira...

(...) Outro assunto que devemos resolver pela lista: se terá ou não reunião na próxima segunda-feira. É que nem o Marcus, nem o MSC, nem a DSH estarão lá (...). Na opinião deveríamos fazer a reunião, para que possamos expor o nosso "roteiro" da primeira atividade do Aplicação (...) e construir uma atividade com as duas novas idéias (ou discutir outras). Estou esperando resposta de todos sobre a reunião.

\section{Mensagem 58: lista LabMatPesq}

Mas o acordo entre iguais também se evidencia quando o grupo, ao compartilhar o esboço o planejamento, se mostra aberto e solicita "sugestões" e "novas idéias", como na mensagem 64. O planejamento não é, portanto, resultado apenas do esforço individual de cada um. Ele representa uma síntese, ainda que provisória, do trabalho coletivo.

\section{De: $M A M$}

Assunto: Reunião do dia 29

(...) estruturar a primeira atividade. Bom, ela será realizada primeiramente no computador pelo aplicativo XHOME-Desing; depois os alunos realizarão maquetes.

$1^{a}$ aula - exploração do programa para familiarizá-los com as ferramentas disponíveis e como usá-las, através de um pequeno projeto (sugestão: um quarto, observando a proporcionalidade com o real). Apresentação da proposta de trabalho. $2^{a}$ e $3^{a}$ aulas - construção da casa no programa. $4^{a}$ aula - levantamento e pesquisa de preço do material para a maquete através da internet ou propor na $3^{a}$ aula que tragam uma pesquisa de preços em livrarias do material necessário. $5^{a}$ aula - discussão entre os grupos e análise de preços para o orçamento mais vantajoso. Planejamento da maquete (união das casas em um quarteirão). $6^{a}$ e $7^{a}$ aulas realização da maquete (tentar fazer em apenas uma). Sugestão: cada grupo em um computador construindo uma casa por grupo. Tempo estimado para realização da atividade: entre 7 e 9 aulas.

Esse é apenas um esboço da atividade. Aceitamos sugestões, uma vez que as aulas estão prestes a começar. Aceitamos, também, novas idéias para outras atividades.

Até segunda-feira no lec ou no próprio Colégio Aplicação. CSC, EDU, MAM

\section{Mensagem 64: lista LabMatPesq}

Além da intensa troca de mensagens neste momento inicial do planejamento, os estudantes da Licenciatura tinham o compromisso de registrar nos seus diários pessoais, o desenvolvimento do trabalho. Em alguns diários, como por exemplo, o da estudante CSC, tais registros contemplaram desde o propósito para realizar determinada atividade, passando por aspectos globais do trabalho e chegando até o nível de interpretar a produção de algum aluno ou grupo de alunos do CAp-Amora. Observações quanto ao trabalho colaborativo das crianças e a necessidade de replanejar ações também são objeto das reflexões de CSC. Uma tomada de consciência importante ocorreu durante o processo de aprendizagem dos estudantes da Licenciatura e que em muitos discursos pedagógicos não ultrapassa o nível do próprio discurso: os alunos, sendo diferentes, aprendem de maneiras diferentes, em tempos e ritmos diferentes. Por isso, ainda que as propostas das Assessorias, como a criação do orçamento ou a construção do glossário de formas e objetos geométricos, sejam desenvolvidas por todos os alunos do CApAmora, as diferenças são, não apenas respeitadas mas compreendidas pelos Assessores, o que os leva a pensar que as "perguntas vão ser feitas de acordo com o trabalho realizado por cada grupo".

De: $R C V$

Assunto: Planejamento

Na reunião de segunda-feira planejamos para a próxima aula dos grupos verde e amarelo, a continuação da construção da maquete. Se sobrar tempo, vamos pedir que cada grupo apresente sua maquete para a turma, falem sobre a escala que utilizaram, expliquem as modificações (se houver) que fizeram e os motivos que as causaram.Além disso,ainda nos grupos, vamos elaborar perguntas do tipo: Se a escala utilizada fosse 3/100, como ficariam as medidas da maquete? Estas perguntas vão ser feitas de acordo com o trabalho realizado por 
cada grupo, (...)

\section{Mensagem 192: lista LabMatPesq}

\section{Conclusões}

Uma das conclusões que podem ser tiradas desse estudo é o impacto que a vivência em um universo escolar exerce sobre a construção da identidade profissional desses estudantes de licenciatura. Dentre possíveis fatores para tal construção, elencamos a experiência realizada como professores na qual esses licenciandos lidaram efetivamente com o ato de ensinar e de analisar a aprendizagem dos alunos com os quais trabalharam.

Afirmar que tal experimento poderia ser replicável e que os mesmos dados seriam obtidos, não seria verdadeiro basicamente por um único aspecto: os envolvidos, tanto licenciandos quanto estudantes do ensino fundamental seriam outros. No entanto, existirão invariantes em termos de uma sistemática na metodologia de formação desses futuros professores e que, da mesma forma que com o grupo analisados, viesse a contribuir para a formação deles? A busca por tal resposta está sendo objeto de análise com dados obtidos durante os anos de 2006 e 2007 e será objeto de futuro trabalho. No entanto, preliminarmente, podemos afirmar que os primeiros resultados da análise desses novos dados, sugerem que a utilização dos recursos das tecnologias de informação e comunicação estão "mais incorporados" nas vivências desses novos futuros novos professores.

Para encerrar, retomando a proposta, apresentada anteriormente, de formação de futuros professores, na qual eles criam e exercitam novas práticas em Escolas, trabalham em equipe no planejamento de projetos e exercícios a serem desenvolvidos com crianças, utilizam os recursos digitais oferecidos pelas novas tecnologias tanto no planejamento com seus colegas quanto no trabalho com alunos em Escolas, os dados corroboram um dos aspectos essenciais para a formação de professores de Matemática, qual seja, o de contribuir para a promoção de reflexões pedagógicas, acompanhadas de mudanças, por parte dos futuros professores. Essa afirmação está fortemente baseada nos resultados a que chegam os alunos do ensino fundamental e isso, por sua vez, exerce um impacto sobre as concepções dos estudantes da Licenciatura em matemática quanto ao ensinoaprendizagem de Matemática. Isto confirma uma das hipóteses levantadas anteriormente: que a transformação do currículo, provocando alterações nos padrões de trabalho dos professores e alunos, cria condições para modificações aspectos na formação dos futuros professores.

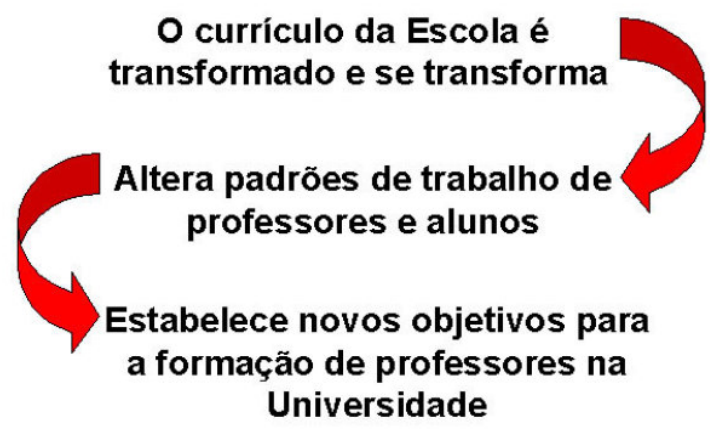

Figura 3: duplo movimento de formação/transformação

Mas é necessário fazer uma ressalva. A proposta implementada não exerce efeitos na direção do rompimento de paradigmas de ensino-aprendizagem sobre todos os estudantes (futuros professores). Alguns são refratários a toda e qualquer proposta que represente a possibilidade de romper com suas crenças a respeito do ensinoaprendizagem em Matemática. Como contrapartida, para os poucos alunos refratários, temos aqueles que estão predispostos a romperem com suas crenças sobre aprendizagem de Matemática. Identificamos que os alunos que demonstraram maior flexibilidade para estabelecer esses rompimentos foram aqueles que efetivamente passaram pelo processo de colocar-se na posição de seus alunos. Isto não somente lhes deu condições para entenderem as características dos alunos com os quais trabalharam, 
como tornou mais clara o que precisava ser feito para contribuir para a aprendizagem desses alunos. Os resultados aqui apresentados também apontam para um aspecto que considero fundamental na formação de professores de Matemática: a necessidade de valorizar desde o início da formação do licenciando em Matemática a prática e o uso de recursos digitais aliado a orientação para o desenvolvimento de planejamentos de propostas de ensino-aprendizagem realizadas de forma cooperativa.

Como perspectiva, reafirmamos a necessidade de tomar os novos dados e confrontá-los com os já existentes e que, nesse momento, nos permitem obter essas conclusões provisórias.

\section{Referências}

Basso, M. V.A. Espaços de Aprendizagem em Rede: novas orientações na formação de Professores de Matemática. PGIE-UFRGS, Porto Alegre, 2003.

Comenius. Didactica Magna. Martins Fontes: São Paulo, 1997.

Damásio, António. O Mistério da Consciência: Do Corpo e das Emoções ao Conhecimento de Si. Companhia das Letras: São Paulo, 2000.

Delors, J. La Educación Encierra Un Tesoro. UNESCO, 1993.

Fagundes, L. C. Informática e Educação In VIII Congresso da Sociedade Brasileira de Computação. Universidade Federal do Rio de Janeiro: Rio de Janeiro, 1988.

Grize, J. Et Al. Inventários de Jean Piaget. Editorial Estampa: Lisboa, 1981.

http://mathematikos.psico.ufrgs.br

http://mathema.psico.ufrgs.br

Piaget, J et al. La Epistemologia del Espacio. El Ateneo: Buenos Aires, 1971.

Piaget, Jean. Para Onde Vai a Educação? José Olympio Editora: Rio de Janeiro, 1984. 